\title{
Targeting CRMP-4 by lentivirus-mediated RNA interference inhibits SW480 cell proliferation and colorectal cancer growth
}

\author{
SI-LE CHEN*, SHI-RONG CAI*, XIN-HUA ZHANG, WEN-FENG LI, ER-TAO ZHAI, JIAN-JUN PENG, \\ HUI WU, CHUANG-QI CHEN, JIN-PING MA, ZHAO WANG and YU-LONG HE
}

\begin{abstract}
Department of Gastrointestinal and Pancreatic Surgery, The First Affiliated Hospital of Sun Yat-sen University, Guangzhou, Guangdong 510080, P.R. China
\end{abstract}

Received January 5, 2014; Accepted February 2, 2016

DOI: $10.3892 /$ etm.2016.3588

\begin{abstract}
The aim of the present study was to investigate the expression level of collapsin response mediator protein 4 (CRMP-4) in human colorectal cancer (CRC) tissue and to evauluate its impact on SW480 cell proliferation, in addition to tumor growth in a mouse xenograft model. Clinical CRC tissue samples were collected to detect the CRMP-4 protein expression levels using western blot and immunohistochemistry analyses. A specific small interfering RNA sequence targeting the CRMP-4 gene (DPYSL3) was constructed and transfected into an SW480 cell line using a lentivirus vector to obtain a stable cell line with low expression of CRMP-4. The effectiveness of the interference was evaluated using western blot and reverse transcription-quantitative polymerase chain reaction, and the cell proliferation was determined using MTT and BrdU colorimetric methods. Tumor growth was assessed by subcutaneously inoculating the constructed cells into BALB/c nude mice. The protein expression levels of CRMP-4 were markedly increased in colon tumor tissue of the human samples. The proliferation of SW480 cells and the tumor growth rate in nude mice of the si-CPMR- 4 group were evidently depressed compared with the si-scramble group. Thus, the present results suggest that CRMP-4 may be involved in the pathogenesis of CRC.
\end{abstract}

\section{Introduction}

Colorectal cancer (CRC) is the third most common malignant tumor in the world, and has a relatively poor prognosis (1).

Correspondence to: Dr Shi-Rong Cai, Department of Gastrointestinal and Pancreatic Surgery, The First Affiliated Hospital of Sun Yat-sen University, 58 Zhongshan Er Road, Guangzhou, Guangdong 510080, P.R. China

E-mail: caishirong@yeah.net

${ }^{*}$ Contributed equally

Key words: collapsin response mediator protein 4, RNA interference, SW480, colorectal cancer
CRC has been strongly associated with lifestyle factors, such as high intake of fat, alcohol or red meat, obesity, smoking and a lack of physical exercise, and accounts for $8 \%$ of all cancer-related mortalities, making it the most common malignancy in developed countries (2) and the fourth most common cause of tumor associated mortality (3). Although chemoprevention or chemotherapy drugs may be a promising approach to reduce the incidence and improve the prognosis of CRC, the clinical application is greatly limited by the development of chemotherapy resistance and the toxic side effects $(4,5)$. The development of CRC involves various genetic and molecular changes in cell proliferation, survival and differentiation, resistance to apoptosis, metastasis and tumor angiogenesis (6). Understanding the etiology of CRC is critical for the treatment of the disease. In recent years, a number of genes, including DPYD (7), UGT1A1 (8) and obesity-related genes (9), have been found to be correlated with the progression of CRC.

Collapsin response mediator protein 4 (CRMP-4) is one of the five members of the CRMP family (CRMP 1-5), which are cytosolic phosphoproteins that are highly expressed in developing human neuronal systems (10). CRMP-4 regulates myelin-dependent axon outgrowth via interaction with glycogen synthase kinase-3 $\beta$, as well as dendrite bifurcation of hippocampal pyramidal neurons (11-13). Recently, CRMP-4 has been reported to be associated with the proliferation, apoptosis, differentiation and invasion of numerous types of cancer cell, such as prostate (14) and pancreatic cancer (15). However, there are currently limited studies that assess the effects of CRMP-4 in SW480 cell proliferation and CRC cell growth. The aim of the present study was to explore the role of CRMP-4 in the progress of CRC, and provide a better understanding for the pathogenesis of $\mathrm{CRC}$. These data may help to discover potential CRC therapeutic targets.

\section{Materials and methods}

Materials and reagents. The human colon carcinoma cell line SW480 was purchased from the Cell Bank of Type Culture Collection of Chinese Academy of Sciences (Shanghai, China). A total of 6 nude mice (BALB/c/nu/nu strain) were obtained from the Laboratory Animal Center of Sun Yat-sen University (Guangzhou, China)). Dulbecco's modified 
Eagle's medium (DMEM), fetal bovine serum (FBS), penicillin and streptomycin were purchased from Invitrogen (Thermo Fisher Scientific, Inc., Waltham, MA, USA). MTT and dimethyl sulfoxide (DMSO) were purchased from Sigma-Aldrich (St. Louis, MO, USA). A BrdU cell proliferation kit (cat. no. K306-200)was purchased from BioVision, Inc. (Milpitas, CA, USA). CRMP-4 (cat. no. 4612) and GAPDH (cat. no. 5174) antibodies were purchased from Cell Signaling Technology, Inc. (Danvers, MA, USA). CRMP-4 primers were synthesized by Invitrogen. Protein quantification (cat. no. YN-P0015-1) and ECL (cat. no. YN-P0017-1) kits were purchased from Guangzhou Yong-Connaught Biological Technology Co., Ltd. (Guangzhou, China). Small interfering lentivirus stable cell lines were constructed by Guangzhou Yong-Connaught Biological Technology Co., Ltd.

Cell culture. SW480 cells were cultured in DMEM supplemented with $10 \%$ FBS, $100 \mathrm{U} / \mathrm{ml}$ penicillin and $0.1 \mathrm{mg} / \mathrm{ml}$ streptomycin. The cells were maintained in a humidified ( $\mathrm{RH}=95 \%$ ) hermetic incubator (cat. no. V103002; Integrated Technologies, Ltd., Ashford, UK) with $5 \% \mathrm{CO}_{2}$ atmosphere at $37^{\circ} \mathrm{C}$. The growth of the cells was observed under an inverted microscope. The cells were subcultured at 2-4 days for one passage and all experiments were performed using cells in the logarithmic growth phase.

Cell viability assay. Cell viability was assessed using an MTT assay. SW480 cells $\left(1 \times 10^{4}\right)$ were seeded in 96-well culture plates at different time points and cultured for $96 \mathrm{~h}$. Next, $10 \mu 1 \mathrm{MTT}(5 \mathrm{mg} / \mathrm{ml})$ was added to each well and further incubated for $4 \mathrm{~h}$. Subsequently, the supernatant was removed and $100 \mu \mathrm{l} /$ well DMSO was added to terminate the reaction. Absorbance was measured using a SpectraMax Plus 384 microplate reader (Molecular Devices, LLC, Sunnyvale, CA, USA) at a wavelength of $570 \mathrm{~nm}$. Cell proliferation was detected using a BrdU proliferation kit in accordance with the manufacturer's instructions, and positive BrdU-labeled cells were thus detected.

Reverse transcription-quantitative polymerase chain reaction (RT-PCR) analysis. Cellular mRNA was isolated from cultured SW480 cells and reversed transcribed to cDNA using a Synthesis System for RT-PCR kit (cat. no. 11904018; Invitrogen), according to the manufacturer's protocol. PCR amplification was performed using the following specific CRMP-4 primers: Upstream, 5'-GACCGTCTCCTTATC AAGGGA-3'; and downstream, 5'-GCATCTGGAAGTGAG TATGGAC- 3 '. The reaction conditions were as follows: $94^{\circ} \mathrm{C}$ for $5 \mathrm{~min} ; 94^{\circ} \mathrm{C}$ for $30 \mathrm{sec} ; 60^{\circ} \mathrm{C}$ for $30 \mathrm{sec} ; 72^{\circ} \mathrm{C}$ for $45 \mathrm{sec}$ (30 cycles) followed by $72^{\circ} \mathrm{C}$ for $10 \mathrm{~min}$. The result of amplification was analyzed by $2 \%$ agarose electrophoresis. The relative expression levels of the target genes were normalized to the GAPDH internal control. All experiments were performed at least three times.

Western blot analysis. A total of 15 patients were recruited from the First Affiliated Hospital of Sun Yat-sen University, patients who were diagnosed with colorectal cancer and had not received any chemotherapy or radiotherapy prior to surgery. From these patients, 50-mg CRC tissue samples were homogenized in $150 \mu 1$ RIPA lysis buffer (Thermo Fisher Scientific, Inc.). Following centrifugation at $14,000 \mathrm{x}$ g for $30 \mathrm{~min}$, the supernatants were collected. Next, SW480 cells were seeded ( $1 \times 10^{6}$ cells/well) in 6-well culture plates and lysed with $200 \mu 1$ lysis buffer, and the cell lysates were collected. The protein concentrations in supernatants of both lysates were determined using Pierce Coomassie Plus (Bradford) Assay Reagent (Thermo Fisher Scientific, Inc.), according to the manufacturer's instructions. Aliquots of lysates were boiled for $5 \mathrm{~min}$ and refrigerated on ice followed by centrifugation at $10,000 \mathrm{x} \mathrm{g}$ for $30 \mathrm{sec}$ and resolved using $10 \%$ SDS-PAGE. Proteins $(30 \mu \mathrm{g})$ in SDS-PAGE were electrotransferred to polyvinylidene fluoride (PVDF) membranes at $100 \mathrm{~V}$ for $1 \mathrm{~h}$. The membranes were blocked with $0.5 \%(\mathrm{~W} / \mathrm{V})$ fat-free milk at room temperature for $1 \mathrm{~h}$ and probed with anti-CRMP-4 antibody (cat. no. ab101009; dilution 1:1,000; Abcam, Cambridge, UK) overnight at $4^{\circ} \mathrm{C}$, with gentle agitation. Then, the membranes were washed with $0.1 \%$ (V/V) Tris-buffered saline and Tween 20 (Thermo Fisher Scientific, Inc.) twice and incubated with mouse anti-human IgG Fc secondary antibody (JDC-10 anti-human IgG Fc; cat. no. ab99757; dilution 1,1000) at room temperature for $1 \mathrm{~h}$. The membranes were washed three times and visualized using the ECL kit. Semi-quantitative analysis was performed to analyzed protein expression.

Immunohistochemical analysis. Immunohistochemistry was performed according to the kit manufacturer's protocol. Tumor sections $(4 \mathrm{~mm})$ were deparaffinized within xylene. Following rehydration, the sections were washed three times with phosphate-buffered saline (PBS) and for $5 \mathrm{~min}$. End peroxidase activity was terminated by the addition of $3 \%(\mathrm{v} / \mathrm{v})$ $\mathrm{H}_{2} \mathrm{O}_{2}$, then the membranes were incubated for $10 \mathrm{~min}$ at room temperature. After three washes with PBS, the sections were blocked with 3\% bovine serum albumin (BSA; Cell Signaling Technology, Inc.) at room temperature for $5 \mathrm{~min}$, followed by $4^{\circ} \mathrm{C}$ overnight incubation with anti-CRMP-4 antibody (dilution, 1:100). After washing three times with PBS, sections were incubated at $37^{\circ} \mathrm{C}$ for $2 \mathrm{~h}$ with secondary antibodies. Finally, sections were counterstained with hematoxylin.

Generation of si-CRMP-4 cell line. The vector LV-008 (Guangzhou Yong-Connaught Biological Technology Co., Ltd) containing an U6 promoter was used to generate small hairpin RNAs. The following oligonucleotides were subcloned into the HpaI/XhoI sites, small hairpin RNA of CRMP-4 (si-CRMP-4). The CRMP-4 shRNA sequences were as follows: Sense, 5'-AACTGCGGCTGCATTTGT GACATTTCAAGAGAATGTCACAAATGCAGCCGCTTT TTTCTCGAGCTCGAGAAAAAAGCGGCTGCATTT GTGACATTCTCTTGAAATGTCACAAATGCAGCCGCA GTT-3'; and antisense, 3'-CTCGAGAAAAAAGCGGCT GCATTTGTGACATTCTCTTGAAATGTCACAAATGCA GCCGCAGTT-5'. Scramble sequence (NC) was used as the control group (si-scramble), the sequence is as follows: Sense, 5'-AACTTTCTCCGAACGTGTCACGTTTCAAGA GAACGTGACACGTTCGGAGAATTTTTTC-3'; and antisense, 3'-TTGAAAGAGGCTTGCACAGTGCAAAGTTCT CTTGCACTGTGCAAGCCTCTTAAAAAAGAGCT-5'. 
A

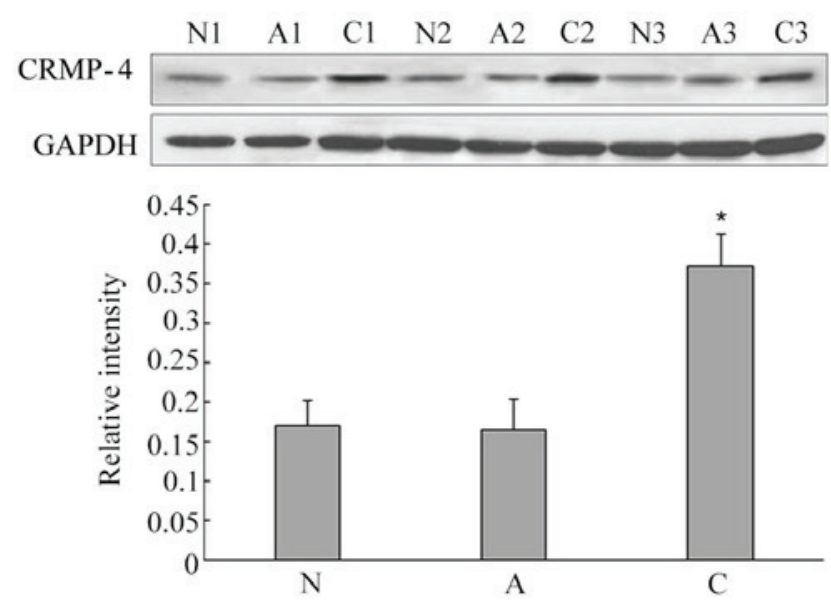

B

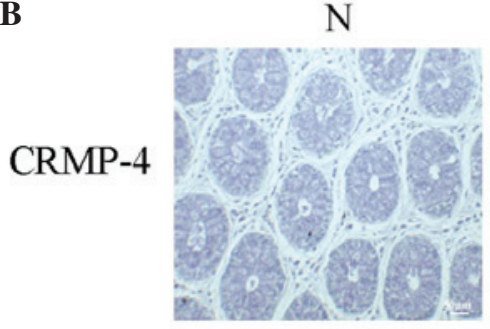

A

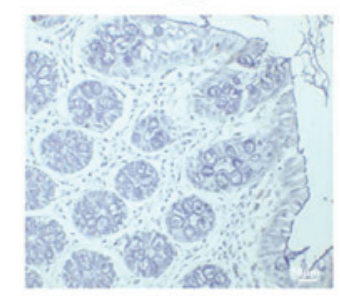

$\mathrm{C}$

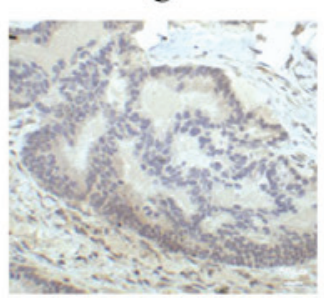

Figure 1. Expression of CRMP-4 in colorectal cancer and control tissues. (A) Western blot analysis of the protein expression of CRMP-4 in tissues from three patients and three healthy individuals, with GAPDH used as a loading control. Data obtained from three independent experiments were normalized against GAPDH and are expressed as the mean \pm standard deviation, as analyzed with one-way analysis of variance. (B) Immunohistochemical analysis of the expression of CRMP-4 in tissues (stain, hematoxylin; magnification, $\mathrm{x} 100$ ). ${ }^{*} \mathrm{P}<0.05$ vs. the $\mathrm{N}$ group. CRMP-4, collapsin response mediator protein 4; N: normal colon tissue from healthy persons, A: normal adjacent tissues of colorectal cancer, $\mathrm{C}$ : colorectal cancer tissue.

Lentiviral production was performed as follows; briefly, HEK 293T cells (China Center for Type Culture Collection, Wuhan, China) were co-transfected with LV-008 and packaging vectors (Guangzhou Yong-Connaught Biological Technology Co., Ltd.), and the resulting supernatant was collected after 48 and $72 \mathrm{~h}$. Lentiviruses were recovered after ultracentrifugation for $1.5 \mathrm{~h}$ at $669 \mathrm{x} \mathrm{g}$ and $4^{\circ} \mathrm{C}$ using an ultracentrifuge (Optima MAX-TL; Beckman Coulter, Inc., Brea, CA, USA) SW 28 rotor and resuspended in PBS. Infectious cells were conducted using $5-10 \mu \mathrm{g} / \mathrm{ml}$ polybrene (Sigma-Aldrich). After $48 \mathrm{~h}$, the cells were cultured in $10 \%$ DMEM with $2 \mu \mathrm{g} / \mathrm{ml}$ puromycin (Sigma-Aldrich) for 10-15 days to generate an si-CRMP-4 stable cell line.

Nude mice tumor xenograft model. SW480 xenografts were established in female nu/nu BALB/c mice (age, 8 weeks; weight, 18-22 g). Mice were bred under specific pathogen-free conditions, with free access to sterilized food and drinking water, in a room with constant temperature $\left(22^{\circ} \mathrm{C}\right), 50-60 \%$ relative humidity and a $12 \mathrm{~h}$ light/dark cycle. The rats were anesthetized ( $8 \mu \mathrm{g} / \mathrm{g} 4 \%$ chloral hydrate; Sigma-Aldrich) during the tumor volume experiment period, and all mice were sacrificed using $4 \%$ chloral hydrate overdose. Nude mice vaccination sites were disinfected with povidone-iodine (Sigma-Aldrich), then these mice were subcutaneously injected in the dorsal scapular region with $200 \mu 1$ cell suspension $\left(2.0 \times 10^{6}\right.$ cells) by the 6th needle. CRMP-4-knockdown cells (si-CRMP-4) and control cells (si-scramble) in $100 \mu \mathrm{l}$ PBS were injected subcutaneously into mice. Tumors were measured once per week using vernier calipers, and tumor volumes were calculated using the following formula: Volume $\left(\mathrm{mm}^{3}\right)=$ length $\mathrm{x}$ width ${ }^{2} \mathrm{x} 0.5$.

Statistical analysis. All results are expressed as the mean \pm standard deviation. One-way analysis of variance was used to analyze the significance between groups. $\mathrm{P}<0.05$ was considered to indicate a statistically significant difference. All statistical analyses were done by using SPSS software (version 19.0; IBM SPSS, Amronk, NY, USA).

Ethical standards. All human studies have been approved by Sun Yat-sen University. All human studies have been performed in accordance with the Helsinki Declaration of 1975. All persons gave their informed consent prior to their inclusion in the study.

\section{Results}

Protein expression of CRMP-4 was increased in colon tumor tissue. In order to observe the expression of CRMP-4, the normal tissue, normal adjacent tissues and tumor tissue of CRC patients after surgery were collected and detected using western blot and immunohistochemistry analysis. Western blot results showed that CRMP-4 protein was significantly increased in cancer tissues (Fig. 1A), compared with normal and paraneoplastic colon tissue. In concurrence with the western blot results, the immunohistochemical analysis results also showed that the expression of CRMP-4 protein was significantly enhanced in cancer and interstitial tissue (Fig. 1B).

Effect of RNA interference (RNAi). To validate the knockdown effect of CRMP-4 on CRC, a shRNA was designed that interfered with CRMP-4 was constructed and implanted into a lentiviral vector. The lentivirus (lv-si-CRMP-4)-interfered CRMP-4 and control virus (lv-si-scramble) were packaged and purified. SW480 cells were infected with these viruses to screen the stable cell line, respectively (Fig. 2A). Furthermore, RT-PCR and western blot analysis were conducted to validate the knockdown efficiency of CRMP-4. As shown in Fig. 2B, CRMP-4 mRNA and protein expression were significantly suppressed by lv-si-CRMP-4 when compared 

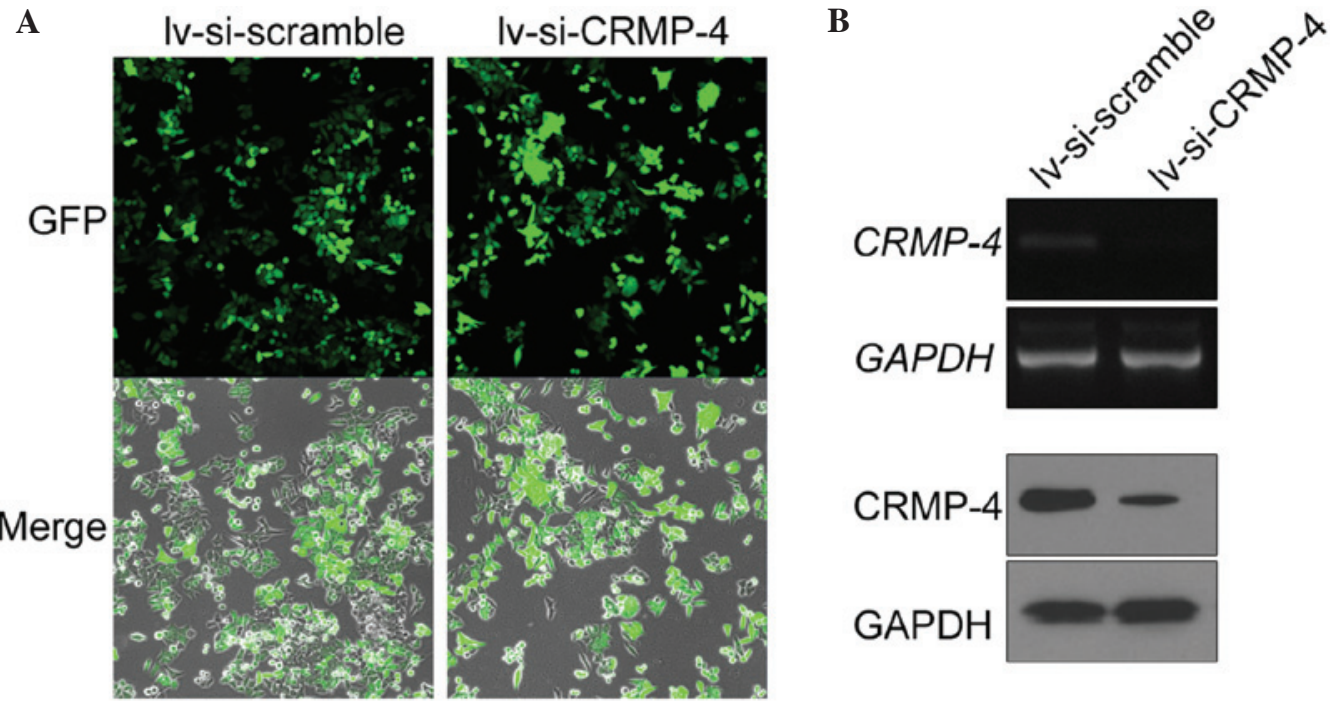

Figure 2. Verification of knockdown CRMP-4 expression by lentivirus. (A) SW480 cells infected with lentivirus. (B) Reverse transcription-polymerase chain reaction and western blot analysis. GAPDH was used as an internal control. CRMP-4, collapsin response mediator protein 4; 1v-si-CRMP-4, SW480 cells infected with lv-si-CRMP-4 lentivirus; lv-si-scramble, SW480 cells infected with lv-si-scramble lentivirus.
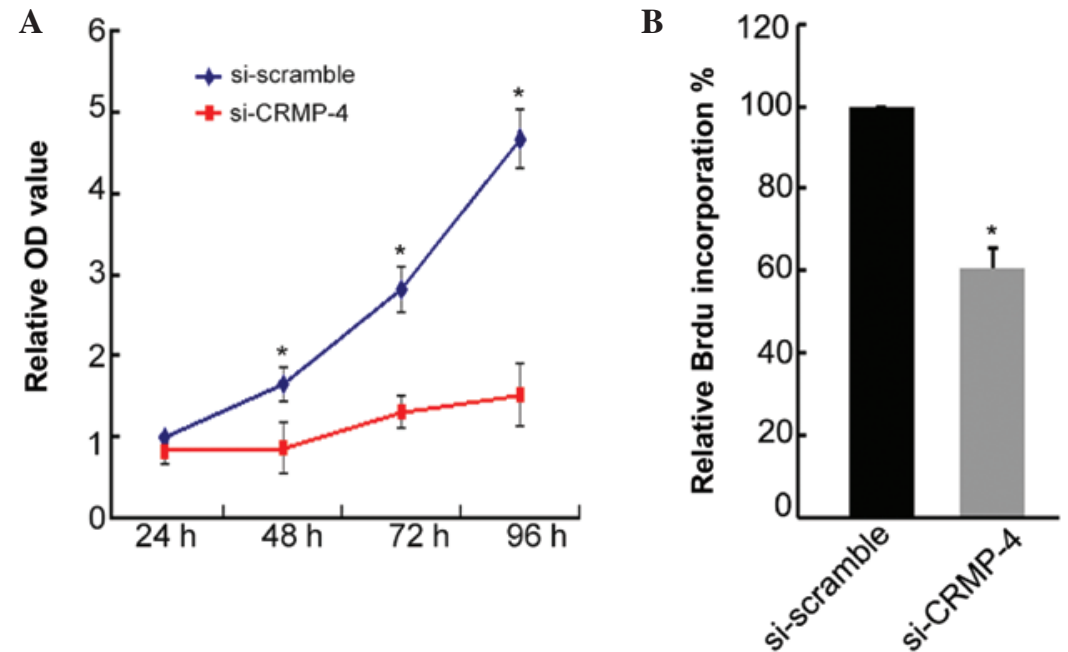

Figure 3. Downregulation of CRMP-4 inhibits the proliferation of SW480 cells. (A) Viability of SW480 cells were evaluated by MTT assay. (B) Proliferation of SW480 cells were evaluated by BrdU incorporation. Data were obtained from three independent experiments and are expressed as the mean \pm standard deviation, as analyzed using one-way analysis of variance. ${ }^{*} \mathrm{P}<0.05$ vs. the si-CRMP-4 group at the same time point. CRMP-4, collapsin response mediator protein 4; OD, optical density.

with the control cells that were infected with lv-si-scramble. These results suggested that the CRMP-4-knockdown cell line (si-CRMP-4) was successfully constructed using the lentiviral vector.

CRMP-4 inhibited proliferation of SW480 cells. In order to investigate the effects of siRNA CRMP-4 on the proliferation in SW480 cells, the changes in cell number of the si-scramble and si-CRMP-4 cells were evaluated using an MTT assay at different time points $(24,48,72$ and $96 \mathrm{~h}$, respectively). The results showed that the absorbance value of SW480 cells decreased significantly in the si-CRMP-4 cells infected with lv-si-CRMP-4 (Fig. 3A). A BrdU incorporation experiment was also conducted to determine whether the downregulation of CRMP-4 inhibits the proliferation of SW480 cells. Similar results were obtained, indicating that the proliferation of the si-CRMP-4 cells was significantly reduced compared with the si-scramble cells (Fig. 3B). These results suggested that the downregulation of CRMP-4 expression inhibits the proliferation of SW480 cells.

Inhibitory effects of siRNA CRMP-4 on CRC growth in vivo. In order to detect the effects of the siRNA targeting CRMP-4 on the growth of colon tumor cells, a nude mice tumor xenograft model was constructed. Mice in different groups were subcutaneously injected with si-CRMP-4 cells or the control si-scramble cells. The results showed that the application of siRNA targeted at CRMP-4 inhibited tumor growth in a xenograft model, which was consistent with the in vitro experiments (Fig. 4). These results suggested that the downregulation of CRMP-4 expression inhibits the growth of colorectal tumor size. 
A

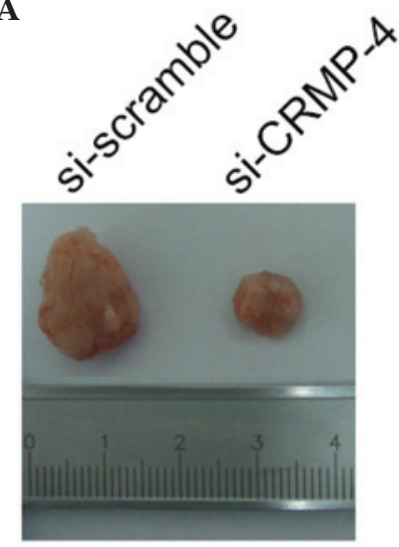

B

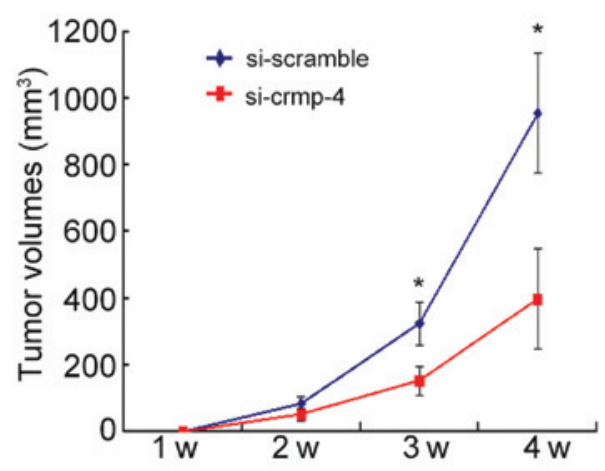

Figure 4. Colon tumor sizes in each group. (A) Colon tumor of mice injected with si-scramble cells or si-CRMP-4 cells after 4 weeks of injection. (B) Colon tumor size in each group after lentivirus injection at 1,2,3 and 4 weeks, respectively. Data were obtained from three independent experiments and are expressed as the mean \pm standard deviation, as analyzed using one-way analysis of variance. ${ }^{*} \mathrm{P}<0.05$ vs. the si-CRMP- 4 group at the same time point. CRMP-4, collapsin response mediator protein 4 .

\section{Discussion}

CRC is among the most common malignant tumors in the world (16). Surgery combined with radiotherapy or chemotherapy is the primary treatment for CRC (17), with high rates of mortality and poor prognosis (2). si-RNA related gene therapies have been investigated in clinical trials for various malignant cancer types (18) and treatment of CRC by gene therapy is a potentially emerging therapy (19). A central challenge of tumor gene therapy is the identification of appropriate and effective targets.

As a member of the CRMP family of cytosolic phosphoproteins, CRMP-4 serves a crucial function in the mediation of semaphorin/collapsin-induced growth cone collapse and regulating the neuronal development and myelin-dependent axon outgrowth (20). Differential expression of CRMP-4 has been observed in numerous types of malignancy $(21,22)$. For example, CRMP-4 was differentially expressed in pancreatic cancer tissues and CRMP-4 silencing reduced cellular invasion, which indicates that CRMP-4 is significantly associated with poor prognosis by promoting liver metastasis and may serve as a novel therapeutic target for pancreatic cancer (15). CRMP-4 expression was inversely associated with the lymph node metastasis of prostate cancer, and its overexpression is able to suppress the invasion ability of prostate cancer cells and inhibited tumor metastasis, which showed that CRMP-4 may provide novel mechanistic insights into metastasis and therapeutic potential for prostate cancer (14). Due to the central role of CRMP-4 in these reported malignant cancers, it may be critical factor in the development of CRC. Thus, the present study aimed to elucidate the association between CRMP-4 was CRC cell development.

RNAi has become a powerful tool for gene knockdown and for elucidating gene function (23). RNAi can induce post-transcriptional gene silencing through RNA-RNA binding and transcriptional gene through RNA-DNA binding (24). It has been widely speculated that shRNA-mediated gene silencing can be a reliable approach for screening gene function and drug-target identification or validation (25-27).
In the present study, western blot and immunohistochemistry were used to evaluate the expression of CRMP-4 in normal tissue, normal adjacent tissues and tumor tissue of CRC patients. The CRMP-4 gene was shown to be upregulated in cancer tissues. To further investigate whether CRMP- 4 is an important factor in CRC cell proliferation, SW480 cells were cultured and cell viability were tested by MTT assay. Furthermore, the shRNAs were designed to downregulate the expression of CRMP-4 in SW480 cells, and was used for the tumor xenograft CRC nude mice model in vivo. In present results showed that knockdown of CRMP-4 expression using a lentivirus significantly suppressed the proliferation of the SW480 cells, and inhibited tumor growth in nude mice. A previous study showed that CRMPs may be involved in cancer invasion (28). Among the members in CRMPs family, CRMP-1 has been proposed to be a lung cancer invasion suppressor gene (29). CRMP-2, which is crucially involved in T-lymphocyte function, has been identified as a potential biomarker for colorectal carcinoma by comparative analysis of cancer cell secretomes $(30,31)$. A loss-of-function screening at high-throughput level showed that CRMP-2 is a negative regulator of p53, exhibiting oncogenic activity (32). In addition, in association with signaling transduction, CRMPs are potentially associated with numerous cellular activities, including proliferation and migration (33). As CRMP-4 has not previously been reported as a marker of $\mathrm{CRC}$, the present study may offer novel insights for aiding the development of CRC therapies.

In conclusion, the knockdown of CRMP-4 by lentivirus is able to suppress the proliferation of SW480 cells and the growth rate of CRC in vivo. These results suggest that CRMP-4 may be a potential biomarker for use in CRC treatment. In particular, gene therapy for CRC using RNAi technology based on CRMP-4 targeting may be of value and requires further investigation.

\section{Acknowledgements}

This study was supported by National Natural Science Foundation of China (grant no. 81372341). Thanks are due to 
Guangzhou Yong-Connaught Biological Technology Co., Ltd. for assistance with the experiments and for valuable discussion.

\section{References}

1. Chan AT and Giovannucci EL: Primary prevention of colorectal cancer. Gastroenterology 138: 2029-2043. e10, 2010.

2. Half $\mathrm{E}$ and Arber N: Colon cancer: Preventive agents and the present status of chemoprevention. Expert Opin Pharmacother 10: 211-219, 2009.

3. Fathi M, Taghikhani M, Ghannadi-Maragheh M and Yavari K: Demonstration of dose dependent cytotoxic activity in SW480 colon cancer cells by ${ }^{177} \mathrm{Lu}$-labeled siRNA targeting IGF-1R. Nucl Med Biol 40: 529-536, 2013.

4. Mésange P, Poindessous V, Sabbah M, Escargueil AE, De Gramont A and Larsen AK: Intrinsic bevacizumab resistance is associated with prolonged activation of autocrine VEGF signaling and hypoxia tolerance in colorectal cancer cells and can be overcome by nintedanib, a small molecule angiokinase inhibitor. Oncotarget 5: 4709-4721, 2014.

5. Zhang X, Sun B and Lu Z: Evaluation of clinical value of single nucleotide polymorphisms of dihydropyrimidine dehydrogenase gene to predict 5-fluorouracil toxicity in 60 colorectal cancer patients in China. Int J Med Sci 10: 894-902, 2013.

6. Pan MH, Lai CS, Wu JC and Ho CT: Molecular mechanisms for chemoprevention of colorectal cancer by natural dietary compounds. Mol Nutr Food Res 55: 32-45, 2011.

7. Tao YL: Research progress of DPYD gene variation in colorectal cancer. Zhong Liu Yan Jiu Yu Lin Chuang 26: 206-209, 2014 (In Chinese).

8. Suenaga M, Fuse N, Yamaguchi T, Yamanaka Y, Motomura S, Matsumoto H, Hamamoto Y, Mizunuma N, Doi T, Hatake K, et al: Pharmacokinetics, safety, and efficacy of FOLFIRI plus bevacizumab in Japanese colorectal cancer patients with UGT1A1 gene polymorphisms. J Clin Pharmacol 54: 495-502, 2014.

9. Rezaei-Tavirani M, Safaei A and Zali MR: The association between polymorphismsin insulin and obesity related genesand risk of colorectal cancer. Iran J Cancer Prev 6: 179-185, 2013.

10. Schmidt EF and Strittmatter SM: The CRMP family of proteins and their role in Sema3A signaling. Adv Exp Med Biol 600: $1-11,2007$.

11. Alabed YZ, Pool M, Ong Tone S and Fournier AE: Identification of CRMP4 as a convergent regulator of axon outgrowth inhibition. J Neurosci 27: 1702-1711, 2007.

12. Alabed YZ, Pool M, Ong Tone S, Sutherland C and Fournier AE: GSK3 beta regulates myelin-dependent axon outgrowth inhibition through CRMP4. J Neurosci 30: 5635-5643, 2010.

13. Niisato E, Nagai J, Yamashita N, Abe T, Kiyonari H, Goshima Y and Ohshima T: CRMP4 suppresses apical dendrite bifurcation of CA1 pyramidal neurons in the mouse hippocampus. Dev Neurobiol 72: 1447-1457, 2012.

14. Gao X, Pang J, Li LY, Liu WP, Di JM, Sun QP, Fang YQ, Liu XP, $\mathrm{Pu} \mathrm{XY}, \mathrm{He} \mathrm{D}$, et al: Expression profiling identifies new function of collapsin response mediator protein 4 as a metastasis-suppressor in prostate cancer. Oncogene 29: 4555-4566, 2010.

15. Hiroshima Y, Nakamura F, Miyamoto H, Mori R, Taniguchi K, Matsuyama R, Akiyama H, Tanaka K, Ichikawa Y, Kato S, et al: Collapsin response mediator protein 4 expression is associated with liver metastasis and poor survival in pancreatic cancer. Ann Surg Oncol 20 (Suppl 3): S369-S378, 2013.

16. Jemal A, Siegel R, Xu J and Ward E: Cancer statistics, 2010. CA Cancer J Clin 60: 277-300, 2010.
17. Nordlinger B, Sorbye H, Glimelius B, Poston GJ, Schlag PM, Rougier P, Bechstein WO, Primrose JN, Walpole ET, Finch-Jones M, et al: Perioperative chemotherapy with FOLFOX4 and surgery versus surgery alone for resectable liver metastases from colorectal cancer (EORTC Intergroup trial 40983): A randomised controlled trial. Lancet 371: 1007-1016, 2008.

18. Burnett JC, Rossi JJ and Tiemann K: Current progress of siRNA/shRNA therapeutics in clinical trials. Biotechnol J 6: 1130-1146, 2011.

19. Ying HQ, Wang F, He BS, Pan YQ, Gao TY, Xu YQ, Li R, Deng QW, Sun HL and Wang SK: The involvement of Kras gene 3'-UTR polymorphisms in risk of cancer and influence on patient response to anti-EGFR therapy in metastatic colorectal cancer: A meta-analysis. Onco Targets Ther 7: 1487-1496, 2014.

20. Quinn CC, Gray GE and Hockfield S: A family of proteins implicated in axon guidance and outgrowth. J Neurobiol 41: 158-164, 1999.

21. Li B, Perabekam S, Liu G, Yin M, Song S and Larson A: Experimental and bioinformatics comparison of gene expression between $\mathrm{T}$ cells from TIL of liver cancer and $\mathrm{T}$ cells from UniGene. J Gastroenterol 37: 275-282, 2002.

22. Zhou W, Xie P, Pang M, Yang B, Fang Y, Shu T, Liu C, Wang X, Zhang L, Li S and Rong L: Upregulation of CRMP4, a new prostate cancer metastasis suppressor gene, inhibits tumor growth in a nude mouse intratibial injection model. Int J Oncol 46: 290-298, 2015.

23. Sen GL and Blau HM: A brief history of RNAi: The silence of the genes. FASEB J 20: 1293-1299, 2006.

24. Lui Z, Ma Q, Wang X and Zhang Y: Inhibiting tumor growth of colorectal cancer by blocking the expression of vascular endothelial growth factor receptor 3 using interference vector-based RNA interference. Int J Mol Med 25: 59-64, 2010.

25. Ghildiyal $M$ and Zamore PD: Small silencing RNAs: An expanding universe. Nat Rev Genet 10: 94-108, 2009.

26. Kim VN, Han J and Siomi MC: Biogenesis of small RNAs in animals. Nat Rev Mol Cell Biol 10: 126-139, 2009.

27. Czech B and Hannon GJ: Small RNA sorting: Matchmaking for argonautes. Nat Rev Genet 12: 19-31, 2011.

28. Pan SH, Chao YC, Chen HY, Hung PF, Lin PY, Lin CW, Chang YL, Wu CT, Lee YC, Yang SC, et al: Long form collapsin response mediator protein-1 (LCRMP-1) expression is associated with clinical outcome and lymph node metastasis in non-small cell lung cancer patients. Lung Cancer 67: 93-100, 2010.

29. Shih JY, Yang SC, Hong TM, Yuan A, Chen JJ, Yu CJ, Chang YL, Lee YC, Peck K, Wu CW and Yang PC: Collapsin response mediator protein-1 and the invasion and metastasis of cancer cells. J Natl Cancer Inst 93: 1392-1400, 2001.

30. Wu CC, Chen HC, Chen SJ, Liu HP, Hsieh YY, Yu CJ, Tang R, Hsieh LL, Yu JS and Chang YS: Identification of collapsin response mediator protein-2 as a potential marker of colorectal carcinoma by comparative analysis of cancer cell secretomes. Proteomics 8: 316-332, 2008.

31. Vincent $P$, Collette $Y$, Marignier R, Vuaillat $C$ Rogemond V, Davoust N, Malcus C, Cavagna S, Gessain A, Machuca-Gayet I, et al: A role for the neuronal protein collapsin response mediator protein 2 in $\mathrm{T}$ lymphocyte polarization and migration. J Immunol 175: 7650-7660, 2005.

32. Llanos S, Efeyan A, Monsech J, Dominguez O and Serrano M: A high-throughput loss-of-function screening identifies novel p53 regulators. Cell Cycle 5: 1880-1885, 2006.

33. Castellani V, Falk J and Rougon G: Semaphorin3A-induced receptor endocytosis during axon guidance responses is mediated by L1 CAM. Mol Cell Neurosci 26: 89-100, 2004. 